\title{
Characteristics of In-Hospital Patients with Congenital Heart Disease Requiring Rapid Response System Activations: A Japanese Database Study
}

\author{
Taiki Haga $^{1, *}$, Tomoyuki Masuyama ${ }^{2}$, Yoshiro Hayashi ${ }^{3}$, Takahiro Atsumi ${ }^{4}$, Kenzo Ishii ${ }^{5}$ and \\ Shinsuke Fujiwara ${ }^{6}$ \\ ${ }^{1}$ Department of Pediatric Critical Care Medicine, Osaka City General Hospital, Osaka, 534-0021, Japan \\ ${ }^{2}$ Department of Emergency and Critical Care Medicine, Jichi Medical University Saitama Medical Center, Saitama, 330-8503, Japan \\ ${ }^{3}$ Department of Intensive Care Medicine, Kameda Medical Center, Chiba, 296-8602, Japan \\ ${ }^{4}$ Department of Emergency Medicine, Seirei Hamamatsu General Hospital, Shizuoka, 430-8558, Japan \\ ${ }^{5}$ Department of Anesthesiology, Intensive Care Unit, Fukuyama City Hospital, Hiroshima, 721-8511, Japan \\ ${ }^{6}$ Department of Emergency Medicine, NHO Ureshino Medical Center, Saga, 843-0393, Japan \\ *Corresponding Author: Taiki Haga. Email: taiki-haga@umin.ac.jp
}

Received: 08 May 2021 Accepted: 30 June 2021

\begin{abstract}
Objectives: This study aimed to study the characteristics of in-hospital deterioration in patients with congenital heart disease who required rapid response system activation and identify risk factors associated with 1-month mortality. Methods: We retrospectively analysed data from a Japanese rapid response system registry with 35 participating hospitals. We included consecutive patients with congenital heart disease who required rapid response system activation between January 2014 and March 2018. Logistic regression analyses were performed to examine the associations between 1-month mortality and other patient-specific variables. Results: Among 9,607 patients for whom the rapid response system was activated, only $82(0.9 \%)$ had congenital heart disease. Only few patients with congenital heart disease were being treated at the cardiology and cardiovascular surgery departments (12.3\% and $9.9 \%$, respectively). Moreover, the incidences of rapid-response events after intensive care unit discharge or surgery were low $(6.8 \%$ and $12.2 \%$, respectively). The most common reason for rapid response system activation was respiratory dysfunction (desaturation: 35.4\%, tachypnoea: $25.6 \%$, and new dyspnoea: 19.5\%). Rapid response system interventions and intensive care unit transfers were required for $65.9 \%$ and $20.7 \%$ of patients, respectively. The mortality rate was $1.2 \%$ at the end of the rapid response system intervention and $11.0 \%$ after 1 month. Moreover, decreased respiratory rate and decreased heart rate at rapid response system activation were associated with increased 1-month mortality. The adjusted odds ratio was 1.10 (95\% confidence interval 1.02-1.19) and 1.02 (95\% confidence interval, $1.00-1.04$ for respiratory rate and heart rate, respectively. Conclusions: Rapid response systems were rarely activated after cardiac surgery and intensive care unit discharge, which were situations with a high risk of sudden deterioration in patients with congenital heart disease. Therefore, encouraging the use of the rapid response system in these departments will enable intervention by a third, specialised team for in-hospital emergencies and help provide comprehensive medical care to patients. Furthermore, 1-month mortality was associated with vital signs at rapid response system activation. These findings may guide treatment selection for patients with congenital heart disease showing deterioration.
\end{abstract}

\section{KEYWORDS}

Heart defects; congenital; emergencies; clinical deterioration; hospital rapid response team; critical care 


\section{Introduction}

The rapid increase in the number of patients with congenital heart disease (CHD) is a serious medical care problem [1]. The incidence of CHD is approximately 7-8 per 1,000 live births [2,3]. These patients exhibit improved survival because of advances in prenatal diagnosis, cardiac surgery, perioperative care, and lifelong healthcare systems; $85 \%-90 \%$ of patients with CHD in high-income countries survive into adulthood [4]. However, this increased survival rate has led to increased adult CHD-related hospitalizations and associated medical costs [5,6] and an elevated risk of in-hospital deterioration.

Patients with CHD frequently have cardiac-specific residual physiologic/anatomic abnormalities and cardiac and non-cardiac sequelae (e.g., arrhythmia, protein-losing enteropathy after Fontan-type operation); furthermore, most of these patients are not completely cured postoperatively [1]. Patients with CHD have higher morbidity and mortality risks than the general population [7,8], as even minor illnesses can quickly become severe. The risk of clinical worsening is particularly high in the perioperative period and after intensive care unit (ICU) discharge [9].

Establishing patient safety systems, including rapid response systems (RRS) for detecting and responding to acute deterioration in patients with CHD, is of priority. An RRS is designed to improve patient outcomes, with specialized teams of critical care-trained professionals working to identify hospitalized patients whose conditions are deteriorating as early as possible in order to prevent serious adverse events, such as cardiac arrest and unexpected death; it consists of four components (afferent, efferent, process improvement and administrative) [10]. Such systems require a comprehensive understanding of the unique and complicated pathophysiology of CHD and the mechanism underlying the progression of the condition. Therefore, in a previous study, we surveyed the actual condition of patients with CHD who required ICU admission after visiting the emergency department (ED) and found that approximately $10 \%$ of patients admitted to the ICU from the ED had CHD, and that some ED diagnoses (e.g., sepsis, arrhythmia) were associated with specific CHD types (e.g., single ventricle anatomy) or postoperative status (e.g., Fontan-type operation) [11]. The deterioration of a patient's condition can occur both outside and inside the hospital; however, few reports present data on in-hospital deterioration among patients with CHD. To our knowledge, there is only one such report from a single institution, which showed that single ventricle physiology in pediatric CHD patients was independently associated with increased mortality [9]. However, we were unable to identify any multicenter studies. Thus, it is still unclear whether the RRS functions effectively in CHD patients. Therefore, this observational study used data from a Japanese multicenter RRS registry to determine key characteristics of patients with CHD and in-hospital deterioration and to identify risk factors for mortality.

\section{Patients and Methods}

\subsection{Study Design and Setting}

This retrospective observational study included data obtained from Japan's In-Hospital Emergency Registry (IHER-J). Institutions are not required to participate in the registry, and the registration items were revised in 2017. In this revision, no changes were made to definitions, classifications, or registration methods. The old database was used from February 2014 to October 2017, and the new database since November 2017. These databases were securely managed by the University Hospital Medical Information Network-Clinical Trial Registry of Tokyo University (Tokyo, Japan), and anonymized data were provided to investigators who submitted research protocols following approval by the IHER-J steering committee. The study protocol conformed to the ethical guidelines of the 1975 Declaration of Helsinki as reflected in a priori approval by the institution's human research committee; it was reviewed and approved by the ethics committees of all 35 participating hospitals in Japan (reference number: 2498 in St. Mariana University School of Medicine, Japan, the representative for IHER-J). The need to obtain informed consent from patients was waived because of the retrospective nature of the study. 


\subsection{Participant Selection}

We included consecutive patients registered in the IHER-J who required RRS activations at 35 hospitals in Japan between January 2014 and March 2018 and had CHD. Only patients with a pre-existing CHD diagnosis were considered to have CHD.

\subsection{Survey Contents}

Several types of data were collected from the IHER-J database. Demographic data included age, sex, height, weight, and code status before RRS activation. RRS data included RRS activation within one week from surgery, surgery details, member activating RRS, RRS activation location, RRS activation reason, vital signs at RRS activation, RRS intervention, RRS intervention details, time from RRS activation to RRS team arrival, RRS activity time, outcomes at the end of RRS intervention, and outcomes one month after RRS intervention. The following items were additionally included in the new database: main clinical department, diagnosis at admission, cause of deterioration, and ICU admission before RRS activation.

\subsection{Statistical Analysis}

Descriptive statistics were used to summarize the characteristics of deteriorating in-hospital patients who activated an RRS. Continuous variables are expressed as medians with interquartile ranges (IQRs), and categorical variables are expressed as frequencies and percentages. Patients with CHD were divided into two groups: those who died within one month after RRS activation and those who survived. Betweengroup differences in continuous and categorical variables were compared using the Wilcoxon rank-sum and Fisher's exact tests, respectively. Multiple logistic regression analyses for age adjustment were performed to examine the associations between 1-month mortality and variables with significant betweengroup differences; the results were presented as crude and adjusted odds ratios (ORs) and $95 \%$ confidence intervals (CIs). All $p$-values were two-sided, and $p$-values of $<0.05$ were considered statistically significant. Statistical analyses were performed using R version 4.0.5 (R Foundation for Statistical Computing, Vienna, Austria; www.R-project.org).

\section{Results}

During the study period, 9,607 patients were registered in the IHER-J database (5,884 and 3,723 patients in the old and new databases, respectively). Among the registered patients, $82(0.9 \%)$ had CHD and were included in this study (Fig. 1). Table 1 presents the characteristics of all patients with CHD who required RRS activation.

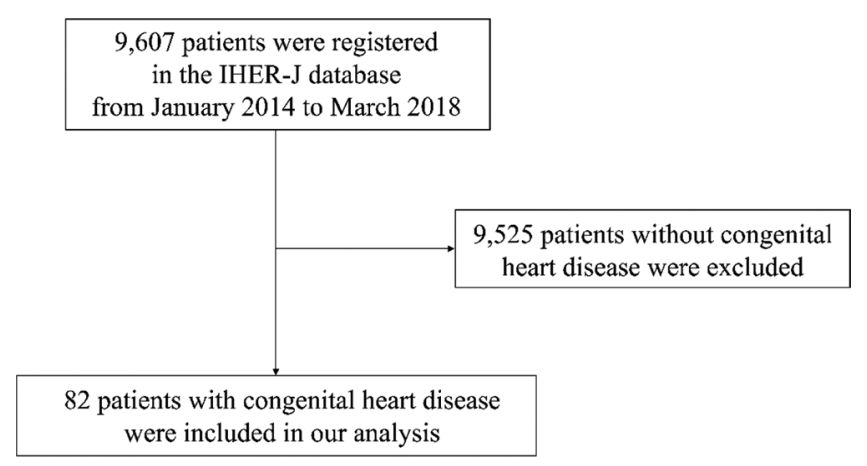

Figure 1: Study enrolment. IHER-J = Japan's In-Hospital Emergency Registry 
Table 1: Characteristics of patients with congenital heart disease with or without 1-month mortality

\begin{tabular}{|c|c|c|c|c|}
\hline Characteristics & $\begin{array}{l}\text { All } \\
(\mathrm{n}=82)\end{array}$ & $\begin{array}{l}\text { Survival } \\
(\mathrm{n}=73)\end{array}$ & $\begin{array}{l}\text { Death } \\
(n=9)\end{array}$ & $p$-value \\
\hline \multicolumn{5}{|l|}{ Demographics } \\
\hline Age in years, median $\left(\mathrm{IQR}^{1}\right)$ & $1.5(0,12)$ & $1(0,12)$ & $5(2,6)$ & 0.18 \\
\hline \multicolumn{5}{|l|}{ Age categories in years, $\mathrm{n}(\%)$} \\
\hline$<1$ & $26(31.7)$ & $25(34.2)$ & $1(11.1)$ & 0.26 \\
\hline $1-6$ & $29(35.4)$ & $23(31.5)$ & $6(66.7)$ & 0.06 \\
\hline $7-12$ & $7(8.5)$ & $7(9.6)$ & $0(0)$ & $>0.99$ \\
\hline $13-17$ & $5(6.1)$ & $5(6.8)$ & $0(0)$ & $>0.99$ \\
\hline$\geq 18$ & $15(18.3)$ & $13(17.8)$ & $2(22.2)$ & 0.66 \\
\hline Male sex, n (\%) & $52(63.4)$ & $47(64.4)$ & $5(55.6)$ & 0.71 \\
\hline Height $(\mathrm{cm})$, median (IQR) & $70(60,103)$ & $70(60,103)$ & $77(68,100)$ & 0.51 \\
\hline Weight (kg), median (IQR) & $\begin{array}{l}8.0(4.5 \\
12.9)\end{array}$ & $\begin{array}{l}7.3(4.4 \\
13.2)\end{array}$ & $\begin{array}{l}9.9(7.8 \\
11.5)\end{array}$ & 0.40 \\
\hline \multicolumn{5}{|l|}{ Main clinical departments } \\
\hline Pediatrics, n (\%) & $21(25.9)$ & $21(29.2)$ & $0(0)$ & 0.10 \\
\hline Cardiology, n (\%) & $10(12.3)$ & $9(12.5)$ & $1(11.1)$ & $>0.99$ \\
\hline Cardiovascular surgery, n (\%) & $8(9.9)$ & $7(9.7)$ & $1(11.1)$ & $>0.99$ \\
\hline Hematology, n (\%) & $6(7.4)$ & $5(6.9)$ & $1(11.1)$ & 0.51 \\
\hline Gastroenterology, n (\%) & $3(3.7)$ & $2(2.8)$ & $1(11.1)$ & 0.30 \\
\hline Gastrointestinal surgery, $\mathrm{n}(\%)$ & $3(3.7)$ & $3(4.2)$ & $0(0)$ & $>0.99$ \\
\hline Respiratory medicine, $\mathrm{n}(\%)$ & $1(1.2)$ & $1(1.4)$ & $0(0)$ & $>0.99$ \\
\hline Neurology, n (\%) & $1(1.2)$ & $1(1.4)$ & $0(0)$ & $>0.99$ \\
\hline Neurosurgery, n (\%) & $2(2.5)$ & $2(2.8)$ & $0(0)$ & $>0.99$ \\
\hline Orthopedic surgery, n (\%) & $2(2.5)$ & $2(2.8)$ & $0(0)$ & $>0.99$ \\
\hline Others (internal medicine), $\mathrm{n}(\%)$ & $16(19.8)$ & $12(16.7)$ & $4(44.4)$ & 0.07 \\
\hline Others (surgery), n (\%) & $8(9.9)$ & $7(9.7)$ & $1(11.1)$ & $>0.99$ \\
\hline Diagnosis on admission & & & & 0.09 \\
\hline Medical disease (circulatory), n (\%) & $13(29.5)$ & $13(30.2)$ & $0(0)$ & \\
\hline Medical disease (non-circulatory), n (\%) & $8(18.2)$ & $8(18.6)$ & $0(0)$ & \\
\hline Infectious disease, $\mathrm{n}(\%)$ & $11(25.0)$ & $11(25.6)$ & $0(0)$ & \\
\hline Surgical disease (circulatory), n (\%) & $5(11.4)$ & $5(11.6)$ & $0(0)$ & \\
\hline Surgical disease (non-circulatory), n (\%) & $2(4.5)$ & $1(2.3)$ & $1(100)$ & \\
\hline Malignant tumor, n (\%) & $3(6.8)$ & $3(7.0)$ & $0(0)$ & \\
\hline Others, n (\%) & $2(4.5)$ & $2(4.7)$ & $0(0)$ & \\
\hline Code status before $\mathrm{RRS}^{2}$ activation & & & & $<0.001$ \\
\hline Full resuscitation, $\mathrm{n}(\%)$ & $70(85.4)$ & $66(90.4)$ & $4(44.4)$ & \\
\hline
\end{tabular}




\begin{tabular}{|c|c|c|c|c|}
\hline Characteristics & $\begin{array}{l}\text { All } \\
(\mathrm{n}=82)\end{array}$ & $\begin{array}{l}\text { Survival } \\
(\mathrm{n}=73)\end{array}$ & $\begin{array}{l}\text { Death } \\
(\mathrm{n}=9)\end{array}$ & $p$-value \\
\hline Partial resuscitation, $\mathrm{n}(\%)$ & $1(1.2)$ & $1(1.4)$ & $0(0)$ & \\
\hline Do not attempt resuscitation, $\mathrm{n}(\%)$ & $6(7.3)$ & $2(2.7)$ & $4(44.4)$ & \\
\hline $\mathrm{N} / \mathrm{A}^{3}, \mathrm{n}(\%)$ & $5(6.1)$ & $4(5.5)$ & $1(11.1)$ & \\
\hline \multicolumn{5}{|l|}{ RRS information } \\
\hline $\mathrm{ICU}^{4}$ admission before RRS activation, $\mathrm{n}(\%)$ & $3(6.8)$ & $3(7.0)$ & $0(0)$ & $>0.99$ \\
\hline $\begin{array}{l}\text { Within } 1 \text { week from operation to RRS activation, } \\
\mathrm{n}(\%)\end{array}$ & $10(12.2)$ & $10(14.7)$ & $0(0)$ & 0.59 \\
\hline Operation details & & & & 0.72 \\
\hline Gastrointestinal, n (\%) & $3(27.3)$ & $3(30.0)$ & $0(0)$ & \\
\hline Orthopedic, n (\%) & $2(18.2)$ & $2(20.0)$ & $0(0)$ & \\
\hline Respiratory, n (\%) & $2(18.2)$ & $1(10.0)$ & $1(100)$ & \\
\hline Neurology, n (\%) & $1(9.1)$ & $1(10.0)$ & $0(0)$ & \\
\hline Cardiovascular, n (\%) & $1(9.1)$ & $1(10.0)$ & $0(0)$ & \\
\hline Others, n (\%) & $2(18.2)$ & $1(10.0)$ & $0(0)$ & \\
\hline Members who activated RRS & & & & $>0.99$ \\
\hline Physician, n (\%) & $15(22.4)$ & $14(23.0)$ & $1(16.7)$ & \\
\hline Nurse, n (\%) & $50(74.6)$ & $45(73.8)$ & $5(83.3)$ & \\
\hline Other medical staff, $\mathrm{n}(\%)$ & $1(1.5)$ & $1(1.6)$ & $0(0)$ & \\
\hline Medical office worker, n (\%) & $0(0)$ & $0(0)$ & $0(0)$ & \\
\hline Others, n $(\%)$ & $1(1.5)$ & $1(1.6)$ & $0(0)$ & \\
\hline Places where RRS was activated & & & & $>0.99$ \\
\hline General ward, n (\%) & $71(86.6)$ & $62(84.9)$ & $9(100)$ & \\
\hline Outpatient department, n (\%) & $5(6.1)$ & $5(6.8)$ & $0(0)$ & \\
\hline Examination room, n (\%) & $3(3.7)$ & $3(4.1)$ & $0(0)$ & \\
\hline Rehabilitation room, n (\%) & $1(1.2)$ & $1(1.4)$ & $0(0)$ & \\
\hline Others, n $(\%)$ & $2(2.4)$ & $2(2.7)$ & $0(0)$ & \\
\hline \multicolumn{5}{|l|}{ Reasons for RRS activation } \\
\hline Desaturation, n (\%) & $29(35.4)$ & $25(34.2)$ & $4(44.4)$ & 0.71 \\
\hline Any concern, $\mathrm{n}(\%)$ & $28(34.1)$ & $24(32.9)$ & $4(44.4)$ & 0.48 \\
\hline Tachypnoea, n (\%) & $21(25.6)$ & $21(28.8)$ & $0(0)$ & 0.10 \\
\hline New dyspnea, n (\%) & $16(19.5)$ & $16(21.9)$ & $0(0)$ & 0.19 \\
\hline Disturbance of consciousness, $\mathrm{n}(\%)$ & $14(17.1)$ & $12(16.4)$ & $2(22.2)$ & 0.64 \\
\hline Tachycardia, n (\%) & $8(9.8)$ & $8(11.0)$ & $0(0)$ & 0.58 \\
\hline Hypotension, n (\%) & $4(9.1)$ & $4(9.3)$ & $0(0)$ & $>0.99$ \\
\hline
\end{tabular}




\begin{tabular}{|c|c|c|c|c|}
\hline Characteristics & $\begin{array}{l}\text { All } \\
(\mathrm{n}=82)\end{array}$ & $\begin{array}{l}\text { Survival } \\
(\mathrm{n}=73)\end{array}$ & $\begin{array}{l}\text { Death } \\
(\mathrm{n}=9)\end{array}$ & $p$-value \\
\hline Bradypnea, n (\%) & $3(3.7)$ & $3(4.1)$ & $0(0)$ & $>0.99$ \\
\hline Anaphylaxis, n (\%) & $2(2.4)$ & $2(2.7)$ & $0(0)$ & $>0.99$ \\
\hline Convulsive seizure, $\mathrm{n}(\%)$ & $1(1.2)$ & $0(0)$ & $1(11.1)$ & 0.11 \\
\hline Oliguria, n (\%) & $1(1.2)$ & $1(1.4)$ & $0(0)$ & $>0.99$ \\
\hline Massive bleeding, n (\%) & $1(2.3)$ & $0(0)$ & $1(0)$ & 0.02 \\
\hline \multicolumn{5}{|l|}{ Causes of deterioration } \\
\hline Respiratory failure, n (\%) & $20(45.5)$ & $20(46.5)$ & $0(0)$ & $>0.99$ \\
\hline Infection, $\mathrm{n}(\%)$ & $8(18.2)$ & $7(16.3)$ & $1(100)$ & 0.18 \\
\hline Suffocation, n (\%) & $5(11.4)$ & $5(11.6)$ & $0(0)$ & $>0.99$ \\
\hline Heart failure, n (\%) & $4(9.1)$ & $4(9.3)$ & $0(0)$ & $>0.99$ \\
\hline Distributive shock, n (\%) & $1(2.3)$ & $1(2.3)$ & $0(0)$ & $>0.99$ \\
\hline \multicolumn{5}{|l|}{ Vital signs at RRS activation } \\
\hline Oxygen saturation (\%), median (IQR) & $\begin{array}{l}95.0(90.0 \\
98.0)\end{array}$ & $\begin{array}{l}97.0(88.3, \\
99.0)\end{array}$ & $\begin{array}{l}93.0(88.3, \\
98.3)\end{array}$ & 0.55 \\
\hline Respiratory rate (breaths per minute), median (IQR) & $22(17,30)$ & $30(24,46)$ & $20(18,26)$ & 0.01 \\
\hline Heart rate (beats per minute), median (IQR) & $93(73,116)$ & $\begin{array}{l}112(97, \\
135)\end{array}$ & $87(83,100)$ & 0.02 \\
\hline Systolic blood pressure (mmHg), median (IQR) & $\begin{array}{l}112(85, \\
137)\end{array}$ & $97(88,116)$ & $\begin{array}{l}110(90 \\
120)\end{array}$ & 0.60 \\
\hline Diastolic blood pressure (mmHg), median (IQR) & $65(50,80)$ & $58(48,69)$ & $60(48,60)$ & 0.45 \\
\hline Body temperature $\left({ }^{\circ} \mathrm{C}\right)$, median (IQR) & $\begin{array}{l}36.9(36.5 \\
37.7)\end{array}$ & $\begin{array}{l}36.8(36.3, \\
37.4)\end{array}$ & $\begin{array}{l}36.8(36.5, \\
37.3)\end{array}$ & 0.94 \\
\hline Glasgow Coma Scale score, median (IQR) & $13(7,15)$ & $\begin{array}{l}15.0 \\
15.0)\end{array}$ & $\begin{array}{l}11.5(7.5 \\
13.3)\end{array}$ & 0.04 \\
\hline RRS intervention, $\mathrm{n}(\%)$ & $54(65.9)$ & $46(63.0)$ & $8(88.9)$ & 0.15 \\
\hline \multicolumn{5}{|l|}{ Details of RRS interventions } \\
\hline Oxygen inhalation, $\mathrm{n}(\%)$ & $20(24.4)$ & $18(24.7)$ & $2(22.2)$ & $>0.99$ \\
\hline Bag valve mask ventilation, $\mathrm{n}(\%)$ & $11(13.4)$ & $8(11.0)$ & $3(33.3)$ & 0.09 \\
\hline Suction, n $(\%)$ & $10(12.2)$ & $8(11.0)$ & $2(22.2)$ & 0.30 \\
\hline Noninvasive positive pressure ventilation, n (\%) & $4(4.9)$ & $3(4.1)$ & $1(11.1)$ & 0.37 \\
\hline Intubation/mechanical ventilation, $\mathrm{n}(\%)$ & $9(11.0)$ & $7(9.6)$ & $2(22.2)$ & 0.25 \\
\hline Bolus infusion, $\mathrm{n}(\%)$ & $12(14.6)$ & $9(12.3)$ & $3(33.3)$ & 0.12 \\
\hline Drug administration, $\mathrm{n}(\%)$ & $13(15.9)$ & $10(13.7)$ & $3(33.3)$ & 0.14 \\
\hline Request for some examinations, $\mathrm{n}(\%)$ & $14(17.1)$ & $11(15.1)$ & $3(33.3)$ & 0.17 \\
\hline Chest compression, $\mathrm{n}(\%)$ & $2(2.4)$ & $2(2.7)$ & $0(0)$ & $>0.99$ \\
\hline
\end{tabular}




\begin{tabular}{|c|c|c|c|c|}
\hline Characteristics & $\begin{array}{l}\text { All } \\
(\mathrm{n}=82)\end{array}$ & $\begin{array}{l}\text { Survival } \\
(\mathrm{n}=73)\end{array}$ & $\begin{array}{l}\text { Death } \\
(\mathrm{n}=9)\end{array}$ & $p$-value \\
\hline $\begin{array}{l}\text { Time from RRS activation to RRS team arrival } \\
\text { (minute), median (IQR) }\end{array}$ & $\begin{array}{l}5.0(3.0 \\
15.0)\end{array}$ & $\begin{array}{l}5.0(2.8 \\
15.0)\end{array}$ & $\begin{array}{l}7.0(4.0 \\
10.0)\end{array}$ & 0.62 \\
\hline RRS activity time (minute), median (IQR) & $\begin{array}{l}20.0(13.5 \\
39.3)\end{array}$ & $\begin{array}{l}20.0(11.8, \\
33.5)\end{array}$ & $\begin{array}{l}36.5(19.3 \\
56.3)\end{array}$ & 0.06 \\
\hline Outcomes at the end of RRS intervention & & & & 0.09 \\
\hline No transfer, $\mathrm{n}(\%)$ & $58(70.7)$ & $53(72.6)$ & $5(55.6)$ & \\
\hline Transfer to ICU, n (\%) & $17(20.7)$ & $15(20.5)$ & $2(22.2)$ & \\
\hline Transfer to high care ward other than ICU, n (\%) & $3(3.7)$ & $2(2.7)$ & $1(11.1)$ & \\
\hline Transfer to a different hospital, $\mathrm{n}(\%)$ & $0(0)$ & $0(0)$ & $0(0)$ & \\
\hline Death, n $(\%)$ & $1(1.2)$ & $0(0)$ & $1(11.1)$ & \\
\hline Others, n $(\%)$ & $2(2.4)$ & $2(2.7)$ & $0(0)$ & \\
\hline Outcomes a month after RRS intervention & & & & $<0.001$ \\
\hline Survival at home, $\mathrm{n}(\%)$ & $35(42.7)$ & $35(47.9)$ & $0(0)$ & \\
\hline Survival in the hospital, $\mathrm{n}(\%)$ & $38(46.3)$ & $38(52.1)$ & $0(0)$ & \\
\hline Death, n $(\%)$ & $9(11.0)$ & $0(0)$ & $9(100)$ & \\
\hline
\end{tabular}

Note: ${ }^{1} \mathrm{IQR}$, interquartile range; ${ }^{2} \mathrm{RRS}$, rapid response system; ${ }^{3} \mathrm{~N} / \mathrm{A}$, not applicable; ${ }^{4} \mathrm{ICU}$, intensive care unit.

\subsection{Characteristics of Patients with CHD Who Required RRS Activation}

The median age of patients with CHD was 1.5 years (IQR, $0-12$ years); approximately $70 \%$ and $20 \%$ of the patients were aged $<7$ years and $\geq 18$ years, respectively. Pediatrics was the most commonly cited clinical department $(25.9 \%)$, followed by internal medicine, cardiology, cardiovascular surgery, and hematology departments $(19.8 \%, 12.3 \%, 9.9 \%$, and $7.4 \%$, respectively). The main diagnoses on admission were circulatory disease $(29.5 \%)$ and infectious disease $(25.0 \%)$. The majority $(85.4 \%)$ of patients with CHD opted for a code status of 'full resuscitation'; $7.3 \%$ had 'DNAR'.

We noted few RRS activations for patients with CHD after ICU discharge or surgery $(6.8 \%$ and $12.2 \%$, respectively). Regarding patients with CHD who required RRS activation after surgery, the most common surgery was gastrointestinal surgery $(27.3 \%)$, followed by orthopedic $(18.2 \%)$ and respiratory surgeries (18.2\%); few patients required RRS activation after cardiovascular surgery $(9.1 \%)$. The RRS was activated most often by a nurse (74.6\%); physicians accounted for approximately $20 \%$ of all RRS activations. The main reasons for RRS activation were related to respiratory concerns (desaturation, tachypnoea, and new dyspnea) and general concern for the patient, even in the absence of vital sign abnormalities. Respiratory failure and infection were the most common reasons for clinical deterioration $(45.5 \%$, and $18.2 \%$, respectively); heart failure was the reason for deterioration in $9.1 \%$ of patients. Among patients with CHD, $65.9 \%$ underwent RRS interventions. The following is a list of RRS interventions in descending order of frequency: oxygen administration, request for additional examinations, drug administration, and bolus infusion $(24.4 \%, 17.1 \%, 15.9 \%$, and $14.6 \%$, respectively); $11.0 \%$ of the patients with CHD required intubation/mechanical ventilation. The outcomes at the end of the RRS intervention were as follows: most patients with CHD (70.7\%) did not require in-hospital transfer to a higher medical care unit, approximately $20 \%$ of patients required transfer to ICU, and the mortality rate was $1.2 \%$. One month after the RRS 
intervention, the patient survival rate was $89.0 \%$ (47.9\% of the patients who survived were discharged, and $52.1 \%$ remained hospitalized); the mortality rate was $11.0 \%$.

\subsection{Associations of 1-Month Mortality with Variables in Patients with CHD}

We divided the 82 registered patients with CHD into a 1-month mortality group $(n=9)$ and a survival group $(n=73)$ (Table 1). There were no significant between-group differences in age, height, weight, and the percentages of males. Regarding code status, patients in the 1-month mortality group were more likely to have selected 'do not attempt resuscitation (DNAR)' and less likely to have selected 'full resuscitation' than were those in the survival group (44.4\% vs. $2.7 \%, P<0.001$, and $44.4 \%$ vs. $90.4 \%, P=0.002$, respectively). At RRS activation, respiratory rate (RR), heart rate (HR), and Glasgow Coma Scale scores were significantly lower in the 1-month mortality group than in the survival group $(P=0.01,0.02$, and 0.04 , respectively). Table 2 shows the association of 1-month mortality with variables that were significantly different between the two groups. One-month mortality was significantly associated with lower RR and lower HR-even after adjustment for age (adjusted OR, 1.10; 95\% CI, 1.02-1.19 and adjusted OR, 1.02; 95\% CI, 1.00-1.04, respectively).

Table 2: Association between 1-month mortality and vital signs at rapid response system activation among deteriorating patients with congenital heart disease

\begin{tabular}{lllll}
\hline $\begin{array}{l}\text { Vital signs at } \\
\mathrm{RRS}^{1} \text { activation }\end{array}$ & $\begin{array}{l}\text { 1-month mortality } \\
(\mathrm{n}=9) \\
\text { Median }\left(\mathrm{IQR}^{4}\right)\end{array}$ & $\begin{array}{l}\text { Survival } \\
(\mathrm{n}=73) \\
\text { Median }(\mathrm{IQR})\end{array}$ & $\begin{array}{l}\mathrm{Crude}^{2} \\
\left(95 \% \mathrm{Cl}^{3}\right)\end{array}$ & $\begin{array}{l}\text { Adjusted OR* } \\
(95 \% \mathrm{CI})\end{array}$ \\
\hline $\begin{array}{l}\text { Oxygen saturation }(\%) \\
\begin{array}{l}\text { Respiratory rate (breaths } \\
\text { per minute) }\end{array}\end{array}$ & $\begin{array}{l}93.0(88.3,98.3) \\
20(18,26)\end{array}$ & $\begin{array}{l}97.0(88.3,99.0) \\
30(24,46)\end{array}$ & $\begin{array}{l}1.01(0.95-1.07) \\
1.10(1.02-1.19)^{\#}\end{array}$ & $1.02(0.99-1.05)$ \\
$\begin{array}{l}\text { Heart rate } \\
\text { (beats per minute) }\end{array}$ & $87(83,100)$ & $112(97,135)$ & $1.02(1.00-1.04)^{\#}$ & $1.02(1.00-1.04)^{\#}$ \\
$\begin{array}{l}\text { Systolic blood pressure } \\
\text { (mmHg) }\end{array}$ & $110(90,120)$ & $97(88,116)$ & $1.0(0.98-1.02)$ & $0.99(0.98-1.02)$ \\
$\begin{array}{l}\text { Diastolic blood pressure } \\
\text { (mmHg) }\end{array}$ & $60(48,60)$ & $58(48,69)$ & $0.98(0.94-1.02)$ & $1.02(0.99-1.05)$ \\
$\begin{array}{l}\text { Body temperature }\left({ }^{\circ} \mathrm{C}\right) \\
\text { Glasgow Coma Scale score }\end{array}$ & $11.5(7.5,13.3)$ & $15.0(11.5,15)$ & $0.9(0.75-1.07)$ & $0.88(0.73-1.06)$ \\
\hline
\end{tabular}

Note: *Adjusted for in the logistic regression analyses were age (years). ${ }^{*}$ The effect of a one-unit decrease in the vital sign on 1-month mortality is shown. ${ }^{1} \mathrm{RRS}$, rapid response system; ${ }^{2} \mathrm{OR}$, odds ratio; ${ }^{3} \mathrm{CI}$, confidence interval; ${ }^{4} \mathrm{IQR}$, interquartile range.

\section{Discussion}

\subsection{Statement of Principal Findings}

This retrospective Japanese database study sought to clarify the actual condition of in-hospital patients with CHD who required RRS activation. First, only $0.9 \%$ of the patients who needed RRS in the Japanese multicenter registry had CHD. Moreover, few of these patients were from the cardiology and cardiovascular surgery clinical departments. Few patients required RRS activation after ICU discharge or postoperatively (6.8\% and $12.2 \%$, respectively). Second, the most common reason for RRS activation in patients with CHD was respiratory distress. Slightly fewer than $70 \%$ of the patients required therapeutic RRS intervention, and approximately $20 \%$ of the patients were transferred to the ICU. Furthermore, the mortality rates at the end of RRS intervention and within one month after RRS intervention were 1.2\% 
and $11.0 \%$, respectively. Finally, 1-month mortality was significantly associated with lower HR and lower RR at RRS activation.

\subsection{Interpretation within the Context of the Wider Literature}

The results of the first group of findings mentioned above indicate that the medical staff in the cardiology and cardiovascular surgery clinical departments seldom activated RRS. Japanese institutions have been slow to implement RRS in facilities wherein patients with CHD are treated (in most cases in Japan, such institutions have PICUs). As of 2019, one survey found that only $41.2 \%$ of all 34 hospitals in Japan with PICUs had RRSs [12]. The implementation of RRSs has been reported to be polarized around the world: in Western countries such as North America, the United Kingdom, and Australia, RRSs have been widely spread and effectively used. On the other hand, other countries, including Japan, are lagging behind in the adoption of RRSs [13]. This is as an obvious challenge in the implementation of RRS for deteriorating patients with CHD in such countries.

Patients with CHD are at a higher risk of sudden deterioration after cardiac surgery and ICU discharge. The percentages of patients who experienced cardiac arrest, hospital death, and readmission were $2.6 \%, 4.0 \%$ [14], and $9.7 \%$ to $11.0 \%$ [15-17], respectively. A survey of rapid-response events associated with pediatric cardiac patients in the United States found that $74 \%$ underwent cardiac surgery before the rapid-response event, and $37 \%$ were admitted to the ICU within seven days before the rapid-response event [9]. These results are discordant with our study findings wherein the percentages of deteriorating patients after surgery or after ICU discharge were $12.2 \%$ and $6.8 \%$, respectively. This might be because Japanese healthcare providers do not appropriately activate RRS at their facility. Additionally, only $9.1 \%$ of all surgeries before RRS activations were cardiac surgeries. According to these divergent results, we concluded that patients with CHD in our study did not have RRS activated in the most critical situations. Furthermore, in our study, only a low percentage of patients with CHD had been in the cardiology and cardiovascular surgery clinical departments during perioperative care and ICU admission. This could indicate that the staff of these departments were reluctant to use the RRS.

A previous report provided a possible reason for the low use of RRSs. Japanese medical culture places high importance on primary care physicians. Further, in Japan, primary care physicians and patients tend to refuse any intervention by third parties, including rapid response teams [12]. RRSs were ineffectively used during the most critical periods, such as after surgery or after leaving ICU; thus, the effective use of RRSs could dramatically improve the prognoses of actively deteriorating patients with CHD in Japan and other countries where RRSs are not as widely used as in Japan.

Regarding the second group of findings mentioned above, few patients in this study were patients in perioperative or post-ICU discharge phases, and the primary clinical departments were not cardiology/ cardiovascular surgery. Respiratory-related symptoms (desaturation, tachypnoea, and new dyspnea) accounted for approximately $80 \%$ of RRS activations. Moreover, respiratory-related disorders, such as respiratory failure and suffocation, were common causes of deterioration in $45.5 \%$ and $11.4 \%$ of the patients, respectively. A previous study of pediatric cardiac patients - most of whom had undergone cardiac surgery - reported that respiratory symptoms triggered only $25 \%$ of rapid-response events; more than half of the events were triggered by other concurrent symptoms of decompensation [9]. This suggests that patients with CHD exhibit varying symptoms of acute decompensation, depending on when the deterioration occurs; multiorgan and respiratory symptoms occur during the postoperative and nonpostoperative periods, respectively. This finding may help treat deteriorating patients with CHD who require a multidisciplinary understanding of their unique and complicated pathophysiological states.

In this study, approximately $70 \%$ of deteriorating patients with CHD required RRS activation; intubation/mechanical ventilation and chest compression were required in $11 \%$ and $2.4 \%$ of deteriorating 
patients, respectively, and $20.7 \%$ of the deteriorating patients were transferred to the ICU. In contrast, a previous study found that pediatric cardiac patients with in-hospital deterioration required more intervention and treatment. Cardiac and/or pulmonary arrest occurred during rapid-response events in $8.5 \%$ of the patients, and $22 \%$ of the patients required ventilation or vasopressor use within $12 \mathrm{~h}$ of transfer to the ICU (defined as 'critical deterioration events'); moreover, 81\% of the patients were transferred to the ICU [9]. Thus, in-hospital deterioration may be more severe in patients with CHD and may require more intensive treatment in the perioperative period. In contrast to the findings regarding severity, in our study, the mortality rate within one month after RRS activation was comparable with that reported in a previous study (11.0\% and $14 \%$, respectively) [9]. This was probably because many patients in our study had opted for the 'DNAR' code status. Among patients who died within one month after the RRS intervention, 44.4\% (4/9) had selected 'DNAR' as the code status. When patients with 'DNAR' $(\mathrm{n}=6)$ code statuses were excluded, the 1-month mortality rate was $6.6 \%(5 / 76)$, which was lower than that in the abovementioned previous study.

One-month mortality was significantly associated with RR and HR at RRS activation. A previous study showed that single ventricle physiology and 'critical deterioration events' are independent predictors of 30day mortality [9]; nevertheless, to the best of our knowledge, no previous study has focused on vital signs as predictors of 1-month mortality in deteriorating pediatric cardiac patients. Generally, the higher the RR or HR, the higher the mortality $[18,19]$. Tachycardia and tachypnoea are usually induced as compensatory responses to hypotension, hypoxia, and metabolic acidosis and are common in patients with severe disease. The PIM-2 [20], PIM-3 [21], PRISM III [22], and PELOD-2 [23] scores, which are representative pediatric severity or mortality prediction scores derived from large observational studies in children, use only blood gas data, ventilator status, hypotension, and/or tachycardia as assessment items for respiration and circulation; they do not use decreased RR and HR that were identified as mortality risk factors in this study. Focusing on the low RR and HR at RRS activation in hospitalized deteriorating patients with CHD may lead to a more appropriate severity assessment, therapeutic intervention, and treatment unit selection.

\subsection{Implications for Policy, Practice, and Research}

The need to improve the ability of medical systems to effectively manage in-hospital deterioration of patients with CHD is urgent. Our results suggest that RRSs were rarely activated after cardiac surgery and ICU discharge when patients with CHD were at a higher risk of sudden deterioration. Therefore, encouraging the use of RRS in such dangerous situations will enable intervention by a third, specialized team for in-hospital emergencies and provide patients with more comprehensive medical care. A more detailed characterization of hospitalized and actively deteriorating patients with CHD requires a larger sample size, a prospective study design, and the adoption of a larger number of variables for subsequent analysis.

\section{Study Strengths and Limitations}

This is the first multicenter report of episodes of in-hospital deterioration requiring RRS in patients with CHD. Contrary to our expectation, there was a high rate of RRS use by departments that do not usually treat congenital heart disease (i.e., other than cardiac surgery and cardiology), a low rate of RRS activation after surgery or ICU discharge, and a high rate of respiratory distress being a reason for RRS activation, which are interesting, new, and previously unreported findings. This study has some limitations. First, there was likely a selection bias as the participating Japanese institutions registered their own data in the database. As of 2019, only four (11.8\%) of all 34 hospitals in Japan with pediatric ICUs (PICUs) used the IHER-J [11]. This could limit the generalizability of our findings. Second, we could extract only predefined variables from the

database. For example, the 'CHD' diagnosis could not be subdivided into detailed subcategories 
(e.g., 'single ventricle physiology'). CHD has a wide spectrum of pathologies. Finally, regarding the items which only exist in either the old or new database, the sample size was consequently small.

\section{Conclusions}

Using the Japanese multicenter RRS registry, we found that RRS was rarely activated for patients with CHD who were deteriorating after surgery and/or ICU discharge. To improve the prognosis of patients with CHD, it might be beneficial to encourage active use of RRSs during the perioperative period and post-ICU discharge when the risk of deterioration is high. Moreover, the decrease in RR and HR at RRS activation, which was identified as mortality risk in this study, may help in the selection of more appropriate treatment in anticipation of worsening conditions.

\section{Collaborators of the In-Hospital Emergency Study Group}

St. Marianna University Hospital (Shigeki Fujitani); NHO Ureshino Medical Center (Shinsuke Fujiwara); Kitazato University Hospital (Masayasu Arai); Osaka City General Hospital (Morooka Takaya); Mie University Hospital (Eiji Kawamoto); Nagoya City University Graduate School of Medical Sciences (Yoshiki Sento); Hiroshima Prefectural Hospital (Takao Yamanoue); JA Hiroshima General Hospital (Natsuo Kawamura); Kyoritsu General Hospital (Yuta Kawase); Kobe City Medical Center General Hospital (Kazuma Nagata); Fukushima Medical University Aizu Medical Center (Takuro Saito); Tomishiro Central Hospital (Masahiro Tamashiro); St. Luke's International Hospital (Kazuhiro Aoki); Hyogo College of Medicine College Hospital (Atsushi Miyawaki); Jichi Medical University Saitama Medical Center (Tomoyuki Masuyama); Shizuoka Children's Hospital (Tatsuya Kawasaki); Japanese Red Cross Musashino Hospital (Shinichiro Suzaki); Seirei Hamamatsu General Hospital (Takahiro Atsumi); Hikone Municipal Hospital (Tomoyuki Ikeda); Fukushima Medical University Hospital (Kazuo Ouchi); Shimane Prefectural Central Hospital (Yuji Yamamori); Kameda Medical Center (Yoshiro Hayashi); Kurashiki Central Hospital (Takanao Otake); Miyazaki Prefectural Miyazaki Hospital (Takeshi Aoyama); Gunma University Hospital (Masaru Tobe); Okayama Saiseikai General Hospital (Toshifumi Fujiwara);

Ibaraki Prefectural Central Hospital (Ryosuke Sekine); Chiba University Graduate School of Medicine (Taka-aki Nakada).

Acknowledgement: We thank the In-Hospital Emergency Committee in Japan, organized by the patient safety promotion committee in Japanese Society of Emergency Medicine, the rapid response system committee in The Japanese Society of Intensive Care Medicine, Japan Resuscitation Council, Japanese Society of Emergency Paediatrics, The Japanese Circulation Society, Japanese Society for Quality and Safety in Healthcare, and Japanese Coalition for Patient Safety for contribution to this study. We also thank the In-Hospital Emergency Study Group for helping with data collection.

Availability of Data and Materials: The data in this article were provided by the IHER-J steering committee under license. Data will be shared by the corresponding author upon reasonable request and with the permission of the IHER-J steering committee.

Funding Statement: This work was supported by the Japan Society for the Promotion of Science KAKENHI (Grant Nos. JP24592755, JP18K16548), the Japanese Society of Intensive Care Medicine, and the Japanese Society of Emergency Medicine.

Conflicts of Interest: The authors declare that they have no conflicts of interest to report regarding the present study. 


\section{References}

1. Warnes, C. A., Williams, R. G., Bashore, T. M., Child, J. S., Connolly, H. M. et al. (2008). ACC/AHA 2008 guidelines for the management of adults with congenital heart disease: Executive summary: A report of the American College of Cardiology/American Heart Association Task Force on Practice Guidelines (writing committee to develop guidelines for the management of adults with congenital heart disease). Circulation, 118(23), 2395-2451. DOI 10.1161/CIRCULATIONAHA.108.190811.

2. Hoffman, J. I., Kaplan, S. (2002). The incidence of congenital heart disease. Journal of the American College of Cardiology, 39(12), 1890-1900. DOI 10.1016/s0735-1097(02)01886-7.

3. Dolk, H., Loane, M., Garne, E., Addor, M. C., Bakker, M. et al. (2011). Congenital heart defects in Europe: Prevalence and perinatal mortality, 2000 to 2005. Circulation, 123(8), 841-849. DOI 10.1161/CIRCULATIONAHA.110.958405.

4. Gurvitz, M. Z., Inkelas, M., Lee, M., Stout, K., Escarce, J. et al. (2007). Changes in hospitalization patterns among patients with congenital heart disease during the transition from adolescence to adulthood. Journal of the American College of Cardiology, 49(8), 875-882. DOI 10.1016/j.jacc.2006.09.051.

5. Opotowsky, A. R., Siddiqi, O. K., Webb, G. D. (2009). Trends in hospitalizations for adults with congenital heart disease in the U.S. Journal of the American College of Cardiology, 54(5), 460-467. DOI 10.1016/j. jacc.2009.04.037.

6. Willems, R., Werbrouck, A., de Backer, J., Annemans, L. (2019). Real-world healthcare utilization in adult congenital heart disease: A systematic review of trends and ratios. Cardiology in the Young, 29(5), 553-563. DOI 10.1017/S1047951119000441.

7. Verheugt, C. L., Uiterwaal, C. S., van der Velde, E. T., Meijboom, F. J., Pieper, P. G. et al. (2010). Mortality in adult congenital heart disease. European Heart Journal, 31(10), 1220-1229. DOI 10.1093/eurheartj/ehq032.

8. Greutmann, M., Tobler, D., Kovacs, A. H., Greutmann-Yantiri, M., Haile, S. R. et al. (2015). Increasing mortality burden among adults with complex congenital heart disease. Congenital Heart Disease, 10(2), 117-127. DOI 10.1111/chd.12201.

9. Bavare, A. C., Rafie, K. S., Bastero, P. X., Hagan, J. L., Checchia, P. A. (2017). Acute Decompensation in pediatric cardiac patients: Outcomes after rapid response events. Pediatric Critical Care Medicine: A Journal of the Society of Critical Care Medicine and the World Federation of Pediatric Intensive and Critical Care Societies, 18(5), 414419. DOI 10.1097/PCC.0000000000001117.

10. Devita, M. A., Bellomo, R., Hillman, K., Kellum, J., Rotondi, A. et al. (2006). Findings of the first consensus conference on medical emergency teams. Critical Care Medicine, 34(9), 2463-2478. DOI 10.1097/01. CCM.0000235743.38172.6E.

11. Haga, T. (2020). Characteristics of patients with congenital heart disease requiring ICU admission from Japanese emergency departments. Pediatric Critical Care Medicine. A Journal of the Society of Critical Care Medicine and the World Federation of Pediatric Intensive and Critical Care Societies, 21(12), e1106-e1112. DOI 10.1097/ PCC.0000000000002440.

12. Haga, T., Kurosawa, H., Maruyama, J., Sakamoto, K., Ikebe, R. et al. (2020). The prevalence and characteristics of rapid response systems in hospitals with pediatric intensive care units in Japan and barriers to their use. International Journal for Quality in Health Care: Journal of the International Society for Quality in Health Care, 32(5), 325-331. DOI 10.1093/intqhe/mzaa040.

13. Wendon, J., Hodgson, C., Bellomo, R. (2016). Rapid response teams improve outcomes: We are not sure. Intensive Care Medicine, 42(4), 599-601. DOI 10.1007/s00134-016-4253-3.

14. Gupta, P., Jacobs, J. P., Pasquali, S. K., Hill, K. D., Gaynor, J. W. et al. (2014). Epidemiology and outcomes after in-hospital cardiac arrest after pediatric cardiac surgery. Annals of Thoracic Surgery, 98(6), 2138-2143. DOI 10.1016/j.athoracsur.2014.06.1032144.

15. Kogon, B., Jain, A., Oster, M., Woodall, K., Kanter, K. et al. (2012). Risk factors associated with readmission after pediatric cardiothoracic surgery. Annals of Thoracic Surgery, 94(3), 865-873. DOI 10.1016/j.athoracsur.2012.04.025.

16. Saharan, S., Legg, A. T., Armsby, L. B., Zubair, M. M., Reed, R. D. et al. (2014). Causes of readmission after operation for congenital heart disease. Annals of Thoracic Surgery, 98(5), 1667-1673. DOI 10.1016/j. athoracsur.2014.05.043. 
17. Smith, A. H., Doyle, T. P., Mettler, B. A., Bichell, D. P., Gay, J. C. (2015). Identifying predictors of hospital readmission following congenital heart surgery through analysis of a multiinstitutional administrative database. Congenital Heart Disease, 10(2), 142-152. DOI 10.1111/chd.12209.

18. Oida, K., Takai, H., Maeda, H., Takahashi, S., Tamai, T. et al. (1990). Plasma thrombomodulin concentration in diabetes mellitus. Diabetes Research and Clinical Practice, 10(2), 193-196. DOI 10.1016/0168-8227(90)90044-t.

19. Kellett, J., Kim, A. (2012). Validation of an abbreviated VitalpacTM Early Warning Score (ViEWS) in 75,419 consecutive admissions to a Canadian regional hospital. Resuscitation, 83(3), 297-302. DOI 10.1016/j. resuscitation.2011.08.022.

20. Slater, A., Shann, F., Pearson, G. (2003). PIM2: A revised version of the Paediatric Index of Mortality. Intensive Care Medicine, 29(2), 278-285. DOI 10.1007/s00134-002-1601-2.

21. Straney, L., Clements, A., Parslow, R. C., Pearson, G., Shann, F. et al. (2013). Paediatric index of mortality 3: An updated model for predicting mortality in pediatric intensive care*. Pediatric Critical Care Medicine: A Journal of the Society of Critical Care Medicine and the World Federation of Pediatric Intensive and Critical Care Societies, 14(7), 673-681. DOI 10.1097/PCC.0b013e31829760cf.

22. Pollack, M. M., Patel, K. M., Ruttimann, U. E. (1996). PRISM III: An updated Pediatric Risk of Mortality score. Critical Care Medicine, 24(5), 743-752. DOI 10.1097/00003246-199605000-00004.

23. Leteurtre, S., Duhamel, A., Salleron, J., Grandbastien, B., Lacroix, J. et al. (2013). PELOD-2: An update of the PEdiatric logistic organ dysfunction score. Critical Care Medicine, 41(7), 1761-1773. DOI 10.1097/ CCM.0b013e31828a2bbd. 